\title{
Maternal sensitivity and social support protect against childhood atopic dermatitis
}

\author{
Nicole L. Letourneau ${ }^{1,2,6^{*}}$, Anita L. Kozyrskyj ${ }^{3}$, Nela Cosic ${ }^{1,2,6}$, Henry N. Ntanda ${ }^{1,2,6}$, Lubna Anis ${ }^{1,2,6}$, \\ Martha J. Hart ${ }^{1,2,6}$, Tavis S. Campbell ${ }^{4}$, Gerald F. Giesbrecht ${ }^{5,6}$ and The APrON Team
}

\begin{abstract}
Background: Many studies have identified associations between qualities of maternal-child relationships and childhood asthma, but few have examined associations with childhood atopic dermatitis (AD), a common precursor to asthma. Moreover, maternal psychological distress, including prenatal and postnatal depression, anxiety and stress, may increase risk, while social support from partners may reduce risk for childhood AD. We sought to uncover the association between maternal-infant relationship qualities (maternal sensitivity towards infant behavioral signals, controlling behavior, and unresponsiveness) and child AD after accounting for risk (i.e., prenatal and postnatal maternal depression, anxiety and stress) and protective (i.e., social support) factors.

Methods: We conducted a secondary analysis of data collected on a subsample of 242 women and their infants enrolled during pregnancy in the ongoing Alberta Pregnancy Outcomes and Nutrition cohort study. Inclusion criteria required mothers to be $>16$ years of age, English speaking and $<22$ weeks gestational age at enrollment. Data on depression, anxiety and stress in the prenatal and postnatal periods and physician diagnosis of childhood AD at 18 months were gathered via maternal report. Maternal sensitivity, unresponsiveness and controlling behaviours were assessed via videotaped observations using the Child-Adult Relationship Experimental (CARE)-Index at 6 months of infant age.
\end{abstract}

Results: Higher maternal sensitivity, or the inability of the mother to appropriately understand and respond to infant needs based on behavioral signals, predicted reduced odds of AD independent of and in combination with low prenatal and postnatal anxiety and high paternal support. After adjustment, higher maternal controlling behaviours and unresponsiveness also predicted greater odds of AD.

Conclusions: Low maternal sensitivity is a risk factor for childhood AD, independently and in combination with perinatal anxiety and low social support. Thus, interventions that improve maternal-infant relationship quality, especially sensitivity, reduce anxiety and improve social support from partners could reduce odds of childhood AD.

Keywords: Atopic dermatitis, Childhood, Maternal-infant relationship, Sensitivity, Responsiveness, Control, Depression, Anxiety, Stress, Social support

\section{Background}

Atopic dermatitis (AD), a hypersensitive skin disease characterized by inflamed and scaly skin lesions, pruritus and skin rash is one of the most common chronic diseases to affect children in Western society [1]. Symptoms often appear by 6 months of age, but $65 \%$ of affected

\footnotetext{
*Correspondence: nicole.letourneau@ucalgary.ca

${ }^{6}$ Child Development Centre, ACHRI Owerko Centre, 3rd Floor, 2888

Shaganappi Trail, Calgary, AB T3B 6A8, Canada

Full list of author information is available at the end of the article
}

children will have symptoms by 18 months of age and in more than $50 \%$ of children, symptoms will persist through 7 years of age [2]. AD symptoms often lead to depression, sleep deprivation, feelings of embarrassment, stigma, social isolation, and restricted ability to own pets or play sports [2,3]. Consequently, AD leads to a diminished quality of life for children [3] and its medical care burdens children, parents and the health care system [4, 5]. Substantial attention has been paid to understanding the risk factors for $\mathrm{AD}$ and their implications in the 
atopic march toward allergic rhinitis and ultimately asthma [2, 6-11]. Given that AD is a potent early warning sign for later atopic diseases, ascertaining qualities of the early environment that may predispose children to $\mathrm{AD}$ is warranted.

A recent systematic review identified early environmental risk factors for childhood $\mathrm{AD}$ to be maternal prenatal psychological distress, including depression, anxiety and stress [12]. A study of 1264 mother-infant pairs revealed that maternal report of prenatal mental status including vitality, vigor, happiness, anxiety, discouragement, nervousness, tiredness, exhaustion and work stress predicted $\mathrm{AD}$ in 2 year olds [13]. A large $(n=23,791)$ cross-sectional study revealed that parental history of diagnosed prenatal and postnatal depression predicted $\mathrm{AD}$ in 6-13 year olds [14]. Maternal depressive symptoms in the postnatal period were associated with $\mathrm{AD}$ in 3-12 month old infants as was postnatal anxiety, particularly about childrearing $(n=40)$ [15]. In several other studies, maternal prenatal stressful life events such as divorce, mourning the death of a loved one, job loss or financial problems were associated with $\mathrm{AD}$ in 3-14 year olds, independent of sociodemographic factors or known atopy risk factors, like allergen exposure [16-18]. Stressful life events during the second half of gestation were found to increase the odds of AD in 14 year olds [17]. To our knowledge studies have not examined the differential impact of prenatal or postnatal depression, anxiety and stress on the development of childhood AD.

Although prenatal and postnatal depression, anxiety and stress are often co-morbid [19-21], they likely exert unique contributions to $\mathrm{AD}$ development. Postnatally depressed mothers often fail to respond appropriately to infant cues, alleviate infant stress and overall, are less sensitive and responsive towards their infants [22-24]. This propensity is widely held responsible for the poor developmental outcomes often observed in children of depressed mothers $[25,26]$. Prenatal psychological distress may also negatively affect the priming of the maternal brain for sensitive, responsive interactions with infants [27]. Maternal ${ }^{1}$ sensitivity is defined as a pattern of behaviour that pleases the infant and increases the infant's comfort and attentiveness and reduces its distress and disengagement [28]. Consistently alleviating infant distress by responding to behavioral signals, such as fussiness due to hunger or fatigue, in a timely fashion is an indicator of high maternal sensitivity, while failing to do so is indicative of low responsiveness [29]. Moreover, high maternal sensitivity and responsiveness are contrary

\footnotetext{
${ }^{1}$ We recognize that mothers are not the only caregivers for children and that relationships with primary caregivers and children are paramount, regardless of gender; however, all research to date and reviewed here has focused on mothers.
}

to maternal behaviours that are overtly or covertly hostile or attempt to overly control the infants' behaviours in everyday interactions [30]. As a result, healthy maternalinfant relationships are typically characterized as sensitive and responsive interactions that are attentive to the infants' needs while remaining non-intrusive and noncontrolling, and contribute to the regulation of the infant's response to stress before the infant is physiologically able to self-regulate [31-33]. In other words, infants develop their ability to regulate their stress response through their relationship with their maternal caregivers, especially during the first 3 years of life $[34,35]$. Caregivers who do not provide sensitive, responsive, non-controlling care promote development of precocious self-regulation, which may have physiological costs, including suppressed immune development [36, 37].

As early as 1999, maternal-infant relationships were theorized to predict and/or compound childhood AD [38]; however, to date, only two studies have examined this theorized association [15, 39]. In contrast, many studies have identified associations between maternal-infant relationships and childhood asthma [40-45]. One study compared children with $(\mathrm{n}=20)$ and without $(\mathrm{n}=20) \mathrm{AD}$, they found that self-reported maternal overprotectiveness and control were associated with AD in 3-12 month olds [15]. Another study compared self-reported relationship characteristics of mothers of children less than 6 years of age with $(n=102)$ and without $(n=131)$ AD and found that mothers of children with $\mathrm{AD}$ were less affectionate and that mothers of children with more severe symptoms were more rejecting and less encouraging of children's autonomy [39]. They also examined maternal sensitivity via parental self-report and failed to find any difference between $A D$ and non-AD groups [39]. However, selfreport measures of maternal-infant relationship quality are poorly correlated with observational measures [46] and thus observations of are much preferred $[47,48]$, yet much ignored in the research on $\mathrm{AD}$ or other atopic diseases. Given the role of $\mathrm{AD}$ in the atopic march and the consistent observation of associations between maternal-infant relationships and childhood asthma, and emerging evidence of associations with $\mathrm{AD}$, ascertaining the influence of qualities of the maternal-child relationship (sensitivity, responsiveness, and control) using observational measures, on $\mathrm{AD}$ would be useful.

Furthermore, existing research has not yet examined protective factors in AD development. Social support has been described as a buffer to stressful life events, enhancing the mother's self-esteem and self-efficacy and aiding in the transition to motherhood, consequently promoting healthy child development $[49,50]$. Social support refers to emotional, affirmational, informational and instrumental assistance, from social relationships including partners 
[51]. Without appropriate social support during the transition to motherhood, this transition can be difficult and distressing, adding to maternal psychological distress and affecting the mother's ability to care for her infant [49]. Lack of social support has been strongly associated with maternal depressive symptoms [51, 52]. Research has affirmed the protective role of social support, particularly from fathers, for normative and depressed mothers [53-56]. To our knowledge, existing research has not yet examined maternal social support as a protective factor in children's AD. Other identified risk factors include parental history of atopic disease $[57,58]$, especially asthma, low maternal education, being a boy [59], high birth weight and day care attendance in the first year of life [60]. Finally, breastfeeding has been shown to predict both increased maternal sensitivity $[53,61]$ and changes in risk of AD [62].

To address the aforementioned gaps in the literature, we sought to determine the association between maternal-infant relationship qualities (sensitivity, responsiveness and control) and child AD by 2 years of age, considering risk (i.e. maternal prenatal and postnatal depression, anxiety and stress) and protective (i.e. social support) factors. Given the prominent role of maternal sensitivity, we also sought to identity predictors of maternal sensitivity. We hypothesized that lower maternal sensitivity, higher unresponsiveness and control would increase the risk for $\mathrm{AD}$ in young children. We also hypothesized that greater symptoms of depression and anxiety and reported stress would predict lower maternal sensitivity and increased risk of childhood AD. Finally, we hypothesized that greater reported postnatal social support would reduce the likelihood of AD.

\section{Methods}

This is a secondary analysis of data from the Fetal Programming Study [63], a sub-study of the larger Alberta Pregnancy Outcomes and Nutrition (APrON) longitudinal pregnancy cohort study. The Fetal Programming Study was designed to examine biomarkers of maternal stress during pregnancy and to collect data on postnatal maternal-infant relationships and other health outcomes [64]. Ethics approvals were obtained from the Conjoint Health Research Ethics Board at the University of Calgary and the Health Research Ethics Board at the University of Alberta, both in Canada. After obtaining informed consent, data were collected in early (1322 weeks) and late (32-40 weeks) gestation and again at 3 (range 2-4 months), 6 (5-8 months) and 18 (range 12-27 months) months postpartum via clinic visits and mailed questionnaires. Trained research assistants conducted clinic visits at the regional children's hospital. No incentives to participation were offered. Details on the full cohort are published [64].

\section{Sample and recruitment}

Between 2011 and 2012, 294 participants were recruited and enrolled in the sub-study, a portion of the final total APrON cohort of 2189 mothers and their infants. See Fig. 1 for details. Due to the nature of observational measurement in the sub-sample, recruitment was constrained to Calgary. Mothers were identified via maternity, ultra sound, family medicine and obstetrics clinics and media advertisements [64]. Participant enrollment eligibility criteria included mothers $<22$ weeks gestational age (GA) at first study visit, $>18$ years of age, not smoking or drinking alcohol during pregnancy, singleton pregnancy, not on any synthetic glucocorticoid medication, and no known fetal complications during study entry [63]. At the 18 month follow-up clinic visit, the sample retained was comprised of 242 mother-infant pairs.

\section{Overview of study variables}

This study collected data on infant AD at the 18 month clinic visit. Extensive data were collected on mothers'

Total births in Alberta between 2009-2012*

\section{6,242}

Period of recruitment for APrON began May, 2009 and ended Jully, 2012

Total participants enrolled in the APrON Study

\section{9}

Of the APrON sample, a subsample of the total number of participants enrolled in the later period (January, 2011 to July, 2012) of APrON recruitment were also enrolled in the Fetal Programming Sub-Study based on additional inclusion criteria, see methods section.

Total participants recruited for the Fetal Programming Sub-Study 294

52 participants were lost due to drop outs or refusal to participate in 18 month clinic visit.

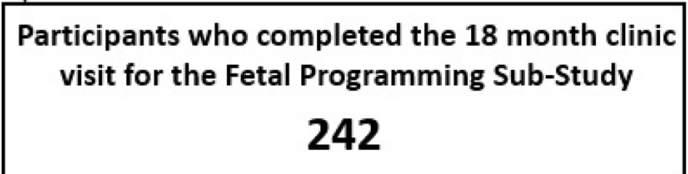

*http://www.statcan.gc.ca/tables-tableaux/sum-som/l01/cst01/h/th85a-eng.htm Fig. 1 Enrollment of individuals through each stage of the study 
demographic characteristics, health history, including maternal history of asthma, prenatal and postnatal maternal psychological distress (anxiety, depression or stress), maternal social support (specifically the extent of partner/spouse support) and children's birth and health outcomes including breastfeeding status (at 3 months) from the APrON surveys completed at prenatal or postnatal clinic visits or sent in by mail. Observations of maternal-infant relationships were conducted at 6 month clinic visits. Covariates included identified risk factors for AD: maternal asthma, low maternal education, being a boy [59], breastfeeding status and birth weight [60]). (Another known covariate, day care attendance in the first year of life, was not included as in our Canadian sample, nearly all the children's parents were on a 1-year parental leave.)

\section{Infant atopic dermatitis}

This was assessed via questionnaire at the 18 month clinic visit during which mothers reported physician diagnosis of infant AD. Mothers were asked to report if their child was diagnosed by a physician with $A D$ in the last 6 months. $\mathrm{AD}$ was thus dichotomized as 1 (AD diagnosis) or 0 (no AD diagnosis) for analysis. In other studies, parent report has yielded high sensitivity, specificity and concordance [65] with corroborated physician diagnosis of AD.

\section{Maternal-infant relationship quality}

Maternal-infant relationship qualities at 6 months of age were assessed with the Child-Adult Relationship Experimental (CARE)-Index, a 5 min observational procedure involving videotaping the mother and child playing with age-appropriate, child-safe toys [28]. Video recordings were coded to attain scores for the constructs of maternal sensitivity, unresponsiveness and control. Possible scores range from 0 to 14, with higher scores indicating more observations of the construct. Moreover, sensitivity maps onto dyadic synchrony, a global measure of maternal-infant relationship quality, and scores may be categorized in the "sensitive" (11-14), "adequate" (7-10), "intervention" (5-6) and "at-risk" (0-4) ranges. The CARE-Index has a high degree of stability and has been well validated [66-71]. Typical inter-rater reliabilities range from $r=0.73-0.95[70,72]$. Author Letourneau is reliable CARE-Index coder and supervised the administration of the measure. Video-recorded observations were coded by blinded, reliable coders who achieved $94.4 \%$ inter-rater reliability agreement on the dominant pattern (sensitivity, control and unresponsiveness). Disagreements were resolved by additional viewings and discussion.
Prenatal and postnatal maternal psychological distress Mothers self-reported ratings of psychological distress (depression, anxiety and stress) via the Edinburgh Depression Scale [73, 74] (EDS), Symptom Checklist-90 item-Revised (SCL-90-R) anxiety subscale [75], Pregnancy-Specific Anxiety Scale (PSAS) [76] and Stressful Life Events Questionnaire (SLEQ) [77]. All were administered in early and late pregnancy, and again at 3 months postpartum, with the exception of the administration of the PSAS only in pregnancy. The 10-item EDS has welldemonstrated reliability and validity with test-retest reliability, and good to moderate correlation with other measures of depression [73, 78, 79]. Measuring general anxiety, the SCL-90-R includes 25 items designed to reflect a symptom inventory of general anxiety [75], for which convergent and divergent validity has been established [80]. The possible range of scores for EDS and SCL-90-R is $0-30$, with higher scores indicative of more severe depression or anxiety [78, 81]. For the SCL-90-R, $\mathrm{T}$-scores were tabulated, with scores greater than or equal to 63 indicating high risk for anxiety. The PSAS, a 10-item self-report instrument, is a reliable measure (Cronbach's alpha $=0.81$ ) [54] of pregnant women's worry regarding personal health, labor and delivery and baby care, with final scores ranging from 0 to 3 . To measure the number of stressors, mothers provided self-reported ratings on the 26-item SLEQ [82, 83], indicating "yes" or "no" to whether they have experienced stressful life events, for example, a death or illness of family member or friend, divorce or separation. The range of possible scores is $0-26$, with higher scores indicating a greater number of stressors. As a checklist, internal reliability or inter-item correlations are difficult to establish; however, content, construct and face validity are well recognized $[82,83]$.

\section{Maternal social support}

Mothers' perceptions of the quality of their partners' (88\% of participants reported on their child's father) social support at 3 months postnatal was assessed via the Social Support Effectiveness Questionnaire (SSEQ), a 35-item measure of emotional/affirmational, informational, instrumental and negative support received over the previous 3 months. Total scores range from 0 to 80 , with higher scores indicating more effective support from partners. The internal consistency for this instrument is strong (Cronbach's alpha $=0.87$ ) when used to distinguish levels of social support for childbearing women $[53,84,85]$.

\section{Data analysis}

The sample characteristics were described using descriptive summaries, including means and standard deviations. 
Predictor variables were dichotomized using percentiles or appropriate cut-offs (e.g. high/low or probable/not probable) to aid interpretability. To gain more insight into the relationship between maternal sensitivity and $A D$, maternal sensitivity was classified into the four standard categories: sensitive, adequate, intervention and at-risk, and scores $\geq 7$ are considered "high" on sensitivity (adequate or sensitive) [28] and plotted against the percentage of children with AD. As no established cut-offs exist for maternal unresponsiveness and control, we used 75th percentile comparisons. Maximum values were used from prenatal and postnatal assessments of depression, anxiety and stress, to attain for example, the maximum depression score for the prenatal period and another maximum score for the postnatal period. These maximums were utilized in all statistical tests. Mean differences in maternalinfant relationship measures across the predictors were examined by using $t$ tests and the association between $\mathrm{AD}$ and potential predictors was investigated using Fisher's Chi square test. To rule out collinearity among the predictors, pairwise correlation amongst the predictors was tested using Pearson tests revealing that all the predictors were fairly or moderately $(-0.35$ to 0.34$)$ correlated and suitable for inclusion in the analysis. Simple logistic regression was employed to identify potential predictors of $\mathrm{AD}$. The predictors that were moderately associated (crude associations) with $\mathrm{AD}(\mathrm{p}<0.25)$ in step one and, as recommended [86], those that have previously shown to be associated with $\mathrm{AD}$ in other studies were selected and included in the multivariable logistic regression model. In the final analysis, two multivariable logistic models were fitted based on the study hypotheses. The first model included maternal sensitivity, maternal asthma and distress to predict AD. In the second model, maternal sensitivity was excluded and replaced with maternal unresponsiveness and control to predict $\mathrm{AD}$. The goodness of fit for both models was assessed using the Pearson Chi square. Missing data were treated with listwise deletion.

\section{Results}

In this affluent study population (Table 1), prenatal depression was found in $23.6 \%$, prenatal anxiety in $24.1 \%$, postnatal depression in $7.1 \%$ and postnatal anxiety in $5.6 \%$ of women. Newborns were full-term, normal weight and predominantly breastfed at 3 months. Asthma was reported in $8.3 \%$ of mothers and $18.1 \%$ of their children had $\mathrm{AD}$, according to maternal report of physician diagnosis at 18 months of age.

\section{Association between maternal-infant relationship quality at 6 months and child AD at 18 months}

Mean scores on the CARE-Index were $5.0(\mathrm{SD}=1.9)$ for maternal sensitivity, $6.3(\mathrm{SD}=3.7)$ for unresponsiveness and 2.7 ( $\mathrm{SD}=3.5)$ for controlling in the context of maternal-infant relationships. Correlations revealed that maternal sensitivity was negatively correlated with the controlling $(\mathrm{r}=-0.19)$ and unresponsive $(\mathrm{r}=-0.33)$ domains of the CARE-Index.

Table 2 outlines descriptive and unadjusted associations among predictors, covariates and both maternal sensitivity at 6 months and AD at 18 months. Significant predictors of high maternal sensitivity ( $21.3 \%$ of sample) were age of women, with women over 30 years being more sensitive, and higher postnatal depressive symptoms, with the mean sensitivity score $(\mathrm{M}=9.50, \mathrm{SD}=1.91)$ of highly symptomatic mothers being higher than the mean sensitivity score $(\mathrm{M}=7.63, \mathrm{SD}=1.07)$ of less symptomatic mothers. The only significant predictor of AD at age 18 months (18\% of sample) was maternal history of asthma.

Figure 2 shows that AD was reported in almost 25\% of toddlers born to mothers scoring in the 'at risk' range of the maternal CARE-Index sensitivity measure, then dropped successively with increases to maternal sensitivity to a prevalence of less than $1 \%$ among toddlers of sensitive mothers.

\section{Association between maternal sensitivity, maternal distress, social support and maternal asthma and child AD at 18 months}

Table 3 presents these data translated into odd ratios; maternal sensitivity was negatively associated with $A D$, such that this allergic skin disorder decreased in offspring by 0.81 for each unit increase in the maternal sensitivity score. Mothers with a history of asthma were also 3.4 times more likely to have a child with AD. When adjusted for maternal asthma status, prenatal or postnatal anxiety, and postnatal depression, the statistical association between maternal sensitivity and childhood AD remained; the odds ratio for $\mathrm{AD}$ further decreased to 0.74 for each unit increase in the maternal sensitivity score. In this model, maternal asthma and postnatal anxiety independently increased the risk for AD. The likelihood of $\mathrm{AD}$ was 0.73 for each unit increase in maternal sensitivity in a final model that also included postnatal social support. In this fully adjusted model, child AD was significantly more likely with prenatal or postnatal anxiety and maternal asthma status; it was inversely related to postnatal depression and postnatal social support. Neither prenatal nor postnatal stress contributed to the models.

\section{Maternal responsiveness and control, maternal distress, maternal asthma and social support associations with $A D$ at 18 months}

Between 20 and $25 \%$ of children had AD when mothers exhibited unresponsive or controlling variants of the maternal-infant relationship, whereas they were 
Table 1 Demographic and descriptive characteristics $(n=242)$

\begin{tabular}{|c|c|c|c|}
\hline Variable & Frequency & Mean score (SD) & Percentage \\
\hline \multicolumn{4}{|l|}{ Maternal sensitivity (0-14) } \\
\hline High ( $\geq 7$; adequate or sensitive) & 51 & $7.76(1.20)$ & 21.3 \\
\hline \multicolumn{4}{|l|}{ Maternal control (0-14) } \\
\hline High (>75th percentile) & 59 & $8.38(1.69)$ & 24.7 \\
\hline \multicolumn{4}{|l|}{ Maternal unresponsiveness (0-14) } \\
\hline High (>75th percentile) & 56 & $10.4(0.66)$ & 23.4 \\
\hline \multicolumn{4}{|l|}{ Atopic dermatitis } \\
\hline Yes & 44 & & 18.2 \\
\hline \multicolumn{4}{|l|}{ Maternal asthma } \\
\hline Yes & 20 & & 8.3 \\
\hline \multicolumn{4}{|l|}{ Family income } \\
\hline Above $\$ 100,000$ & 137 & & 58.1 \\
\hline \multicolumn{4}{|l|}{ Education level } \\
\hline$\geq$ University degree & 173 & & 72.7 \\
\hline \multicolumn{4}{|l|}{ Employment } \\
\hline Full time & 188 & & 80.0 \\
\hline \multicolumn{4}{|l|}{ Marital status } \\
\hline Married & 236 & & 97.5 \\
\hline Mother's age & & $31.2(3.80)$ & \\
\hline Gestational age at birth (weeks) & & $39.2(1.70)$ & \\
\hline Birth weight (g) & & $3355.8(532.9)$ & \\
\hline \multicolumn{4}{|l|}{ Breastfeeding (3 months) } \\
\hline Yes & 205 & & 91.5 \\
\hline \multicolumn{4}{|l|}{ Child sex } \\
\hline Female & 120 & & 50.6 \\
\hline \multicolumn{4}{|l|}{ Pregnancy specific anxiety (0-3) } \\
\hline Probable (>75th percentile) & 58 & $1.34(0.25)$ & 24.1 \\
\hline \multicolumn{4}{|l|}{ Prenatal depression (0-30) } \\
\hline Probable (>9; high depressive symptoms) & 57 & $13.2(3.20)$ & 23.6 \\
\hline \multicolumn{4}{|l|}{ Postnatal depression (0-30) } \\
\hline Probable (>9; high depressive symptoms) & 16 & $13.2(2.86)$ & 7.1 \\
\hline \multicolumn{4}{|l|}{ Postnatal anxiety (T-score) } \\
\hline Probable (T-score $\geq 63$; high risk for anxiety) & 13 & $66.2(2.80)$ & 5.6 \\
\hline \multicolumn{4}{|l|}{ Prenatal \# of stressors } \\
\hline 0 & 103 & & 42.9 \\
\hline 1 & 89 & & 37.1 \\
\hline 2 & 35 & & 14.6 \\
\hline$\geq 3$ & 13 & & 5.4 \\
\hline \multicolumn{4}{|l|}{ Postnatal \# of stressors } \\
\hline 0 & 146 & & 63.2 \\
\hline 1 & 59 & & 25.5 \\
\hline 2 & 19 & & 8.2 \\
\hline$\geq 3$ & 7 & & 3.0 \\
\hline \multicolumn{4}{|l|}{ Postnatal social support (0-80) } \\
\hline High (>50th percentile) & 115 & $68.6(5.40)$ & 48.9 \\
\hline
\end{tabular}

$15 \%$ in their absence (Fig. 3). Unadjusted odds ratios for associations between unresponsiveness and controlling behaviour and $\mathrm{AD}$ were not significant; however, in a fully-adjusted model, independent of maternal asthma, postnatal depression or social support, child AD was 1.3-1.4 times more likely in the presence of maternal 
Table 2 Percentage distribution of descriptive and predictor variables for mothers with high maternal sensitivity at 6 months and child AD at 18 months (Chi square tests)

\begin{tabular}{|c|c|c|c|c|c|c|c|}
\hline & \multirow[t]{2}{*}{$\mathbf{N}$} & \multicolumn{3}{|c|}{$\begin{array}{l}\text { High maternal sensitivity at } 6 \text { months } \\
(n=51)\end{array}$} & \multicolumn{3}{|c|}{$\begin{array}{l}\text { Atopic dermatitis at } 18 \text { months } \\
(n=44)\end{array}$} \\
\hline & & n & $\%$ & p value ${ }^{\infty}$ & $\mathrm{N}$ & $\%$ & p value ${ }^{\infty}$ \\
\hline \multicolumn{8}{|l|}{ Maternal sensitivity (0-14) } \\
\hline High ( $\geq 7$; adequate or sensitive) & 51 & & & & 5 & 9.80 & \\
\hline Low $(<7)$ & 188 & & & & 39 & 20.7 & 0.074 \\
\hline \multicolumn{8}{|l|}{ Maternal asthma } \\
\hline Yes & 20 & 3 & 15.0 & & 8 & 40.0 & \\
\hline No & 222 & 48 & 21.6 & 0.470 & 36 & 16.2 & $0.008^{a}$ \\
\hline \multicolumn{8}{|l|}{ Family income } \\
\hline Below $\$ 100,000$ & 99 & 22 & 22.2 & & 21 & 21.2 & \\
\hline Above $\$ 100,000$ & 137 & 29 & 21.2 & 0.805 & 23 & 16.8 & 0.389 \\
\hline \multicolumn{8}{|l|}{ Education level } \\
\hline$<$ University degree & 65 & 10 & 15.4 & & 14 & 21.5 & \\
\hline$\geq$ University degree & 173 & 41 & 23.7 & $0.190^{\mathrm{a}}$ & 30 & 17.3 & 0.457 \\
\hline \multicolumn{8}{|l|}{ Employment } \\
\hline Part time & 47 & 12 & 25.5 & & 5 & 10.6 & \\
\hline Full time & 188 & 39 & 20.7 & 0.962 & 39 & 20.7 & 0.112 \\
\hline \multicolumn{8}{|l|}{ Marital status } \\
\hline Married & 236 & & & & 42 & 17.8 & \\
\hline Single & 6 & & & & 2 & 33.3 & 0.224 \\
\hline \multicolumn{8}{|l|}{ Mother's age } \\
\hline Below 30 years & 70 & 9 & 12.9 & & 16 & 22.8 & \\
\hline 30 and above & 169 & 42 & 24.8 & $0.030^{\mathrm{a}}$ & 28 & 16.6 & 0.254 \\
\hline \multicolumn{8}{|l|}{ Gestational age } \\
\hline 28-38 weeks & 58 & 14 & 24.1 & & 10 & 17.2 & \\
\hline 39 weeks and above & 170 & 34 & 20.0 & 0.440 & 31 & 18.2 & 0.865 \\
\hline \multicolumn{8}{|l|}{ Child sex } \\
\hline Male & 117 & 21 & 17.9 & & 24 & 20.5 & \\
\hline Female & 120 & 30 & 25.0 & $0.175^{\mathrm{a}}$ & 20 & 16.7 & 0.505 \\
\hline \multicolumn{8}{|l|}{ Birth weight (g) } \\
\hline Below $2500 \mathrm{~g}$ & 12 & 2 & 16.7 & & 3 & 25.0 & \\
\hline $2500 \mathrm{~g}$ and above & 228 & 49 & 21.5 & 1.00 & 41 & 18.0 & 0.465 \\
\hline \multicolumn{8}{|l|}{ Breastfeeding (3 months) } \\
\hline Yes & 205 & 41 & 20.0 & 0.688 & 39 & 19.0 & \\
\hline No & 19 & 5 & 26.3 & & 3 & 15.8 & 0.2383 \\
\hline \multicolumn{8}{|l|}{ Prenatal depression (0-30) } \\
\hline Probable (>9; high depressive symptoms) & 57 & 9 & 15.8 & & 11 & 19.3 & \\
\hline Not probable $(\leq 9)$ & 185 & 42 & 22.7 & $0.738^{\mathrm{a}}$ & 33 & 17.8 & 0.803 \\
\hline \multicolumn{8}{|l|}{ Postnatal depression (0-30) } \\
\hline Probable (>9; high depressive symptoms) & 16 & 4 & 25.0 & & 2 & 12.5 & \\
\hline Not probable $(\leq 9)$ & 210 & 43 & 20.5 & $0.003^{\mathrm{a}}$ & 38 & 18.1 & 0.572 \\
\hline \multicolumn{8}{|l|}{ Pregnancy specific anxiety (0-3) } \\
\hline Probable (>75th percentile) & 58 & 13 & 22.4 & & 14 & 24.1 & \\
\hline Not probable ( $\leq 75$ th percentile) & 183 & 37 & 20.2 & $0.277^{\mathrm{a}}$ & 30 & 16.4 & $0.183^{\mathrm{a}}$ \\
\hline \multicolumn{8}{|l|}{ Postnatal anxiety } \\
\hline Probable (T-score $\geq 63$; high risk for anxiety) & 13 & 4 & 30.8 & & 4 & 30.8 & \\
\hline Not probable $($ T-score $<63)$ & 218 & 45 & 20.6 & $0.426^{\mathrm{a}}$ & 39 & 17.9 & $0.135^{\mathrm{a}}$ \\
\hline
\end{tabular}




\begin{tabular}{|c|c|c|c|c|c|c|c|}
\hline & \multirow[t]{2}{*}{$\mathbf{N}$} & \multicolumn{3}{|c|}{$\begin{array}{l}\text { High maternal sensitivity at } 6 \text { months } \\
(n=51)\end{array}$} & \multicolumn{3}{|c|}{$\begin{array}{l}\text { Atopic dermatitis at } 18 \text { months } \\
(n=44)\end{array}$} \\
\hline & & $\mathbf{n}$ & $\%$ & p value ${ }^{\infty}$ & $\mathrm{N}$ & $\%$ & p value ${ }^{\infty}$ \\
\hline \multicolumn{8}{|l|}{ Prenatal \# of stressors } \\
\hline 0 & 130 & 20 & 15.4 & & 21 & 16.2 & \\
\hline 1 or more & 137 & 31 & 22.6 & 0.314 & 23 & 16.8 & 0.476 \\
\hline \multicolumn{8}{|l|}{ Postnatal \# stressors } \\
\hline 0 & 146 & 27 & 18.5 & & 28 & 19.2 & \\
\hline 1 or more & 85 & 24 & 28.2 & 0.936 & 15 & 17.6 & 0.773 \\
\hline \multicolumn{8}{|l|}{ Maternal control (0-14) } \\
\hline High ( $\geq 75$ th percentile) & 59 & & & & 14 & 23.7 & \\
\hline Low (<75th percentile) & 180 & & & & 30 & 16.7 & $0.224^{\mathrm{a}}$ \\
\hline \multicolumn{8}{|c|}{ Maternal unresponsive (0-14) } \\
\hline High ( $\geq 75$ th percentile) & 56 & & & & 13 & 23.2 & \\
\hline Low (<75th percentile) & 183 & & & & 31 & 16.9 & $0.289^{a}$ \\
\hline \multicolumn{8}{|c|}{ Postnatal social support (0-80) } \\
\hline High ( $\geq 50$ th percentile) & 115 & 20 & 17.4 & & 17 & 14.8 & \\
\hline Low (<50th percentile) & 120 & 30 & 25.0 & $0.145^{\mathrm{a}}$ & 26 & 21.7 & $0.172^{\mathrm{a}}$ \\
\hline
\end{tabular}

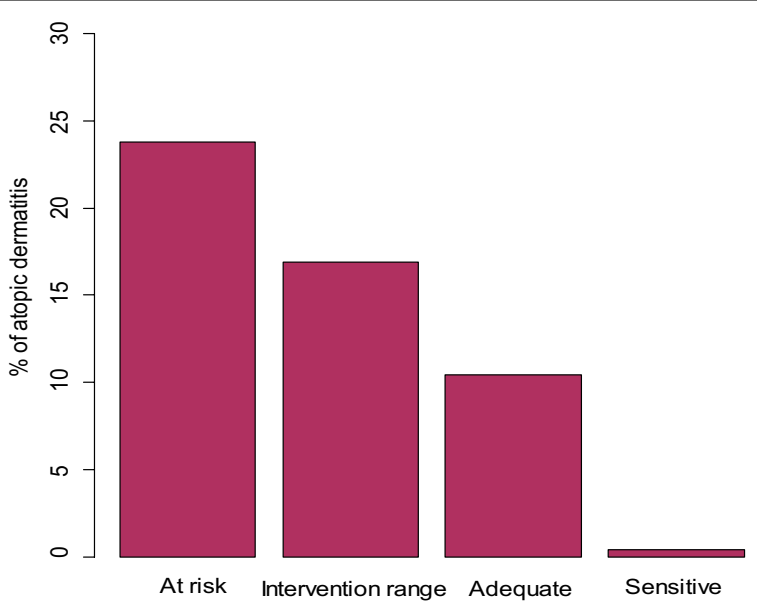

Fig. 2 The more sensitive the mothers in the maternal-infant relationship observations, the fewer children were identified with $A D$. Total $\mathrm{N}=242$

unresponsive and controlling behaviour (Table 4). As with the maternal sensitivity model, AD was independently associated with maternal asthma status, with prenatal and postnatal maternal anxiety, and inversely associated with postnatal depression and social support. Neither prenatal nor postnatal stress contributed to the models.

\section{Discussion}

In a subsample of 242 women and their infants enrolled in the APrON longitudinal study, high maternal sensitivity was found to significantly protect against $A D$ development at 18 months of age (adjusted $\mathrm{OR}=0.73$; $95 \%$ CI 0.56, 0.93, $\mathrm{p}=0.012$ ), independent of maternal asthma status. The maternal sensitivity and child $\mathrm{AD}$ association was also independent of maternal prenatal and postnatal anxiety, and social support. A mother's assessment of the quality of support provided by her partner reduced the onset of this early childhood atopic disorder by 0.96 for every unit increase of perceived support. Maternal anxiety was a risk factor for $\mathrm{AD}$ in offspring. Further, positive associations with child $\mathrm{AD}$ were observed for maternal controlling and unresponsive behaviors (adjusted OR $=1.33,95 \%$ CI 1.03 , $1.71, \mathrm{p}=0.028$ and adjusted $\mathrm{OR}=1.35,95 \% \mathrm{CI} 1.05$, $1.73, \mathrm{p}=0.020$ respectively). Maternal sensitivity was predicted by maternal age above 30 and, in contrast to expectations, higher postnatal depressive symptoms.

Our results suggest that poor maternal-infant relationship quality (low sensitive, high unresponsive and high controlling behavior during interactions with infants) at 6 months of age increases the risk of child $A D$ at 18 months of age. Our findings are consistent with evidence demonstrating the link between maternal-infant relationship quality and child atopic disease, although current understanding is largely limited to the etiology of asthma [40-43, 45]. For example, identified difficulties in the parent-child relationship independently predict asthma onset at 3 and 6 years of age [41], while the onset of asthma in early life has been associated with poor quality relationships with parents that persist into adulthood [87]. 
Table 3 Maternal sensitivity, maternal distress, social support and maternal asthma associations with AD at 18 months

\begin{tabular}{llll}
\hline & Unadjusted OR $\mathbf{( 9 5 \% ~ C l )}$ & Adjusted OR (95\% Cl) $^{\mathbf{b}}$ & Additional adjustment $^{\mathbf{c}}$ \\
\hline Maternal sensitivity & $0.81(0.67-0.98)^{\mathrm{a}}$ & $0.74(0.59-0.93)^{\mathrm{a}}$ & $0.73(0.56-0.93)^{\mathrm{a}}$ \\
Postnatal depression & $0.97(0.87-1.08)$ & $0.93(0.82-1.05)$ & $0.86(0.74-1.00)$ \\
Pregnancy specific anxiety & $1.57(0.76-3.27)$ & $2.02(0.81-5.05)$ & $2.74(1.04-7.19)^{\mathrm{a}}$ \\
Postnatal anxiety & $1.08(0.98-1.18)$ & $1.13(1.01-1.28)^{\mathrm{a}}$ & $1.16(1.01-1.33)^{\mathrm{a}}$ \\
Maternal asthma (ref: no) & $3.44(1.31-9.02)^{\mathrm{a}}$ & $4.35(1.52-12.4)^{\mathrm{a}}$ & $5.35(1.75-16.3)^{\mathrm{a}}$ \\
Postnatal social support & $0.98(0.96-1.01)$ & & $0.96(0.93-0.99)^{\mathrm{a}}$ \\
\hline
\end{tabular}

a Significant values $\mathrm{p}<0.05$

b Adjusted for maternal sensitivity, postnatal depression and anxiety, pregnancy specific anxiety, maternal asthma

c Additional adjustment for maternal sensitivity, postnatal depression, social support and anxiety, pregnancy specific anxiety, maternal asthma

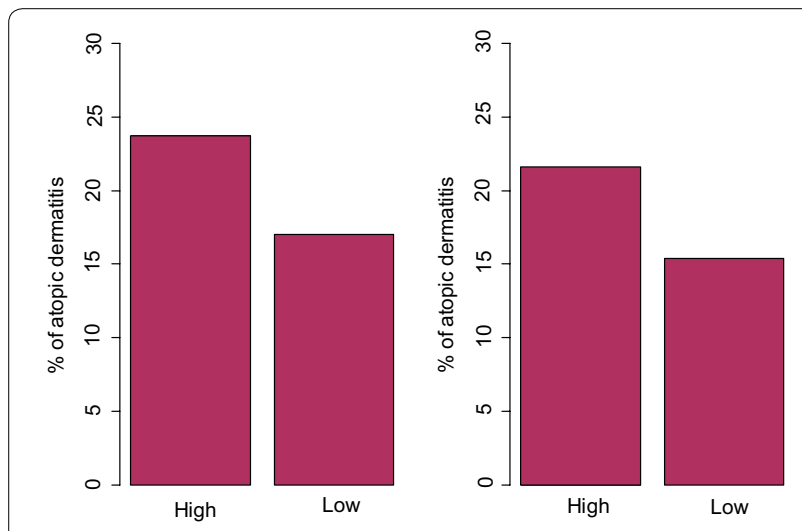

Fig. 3 At high levels of maternal control/unresponsiveness in mother-infant relationship observations, more children have AD than children whose mothers are less controlling/more responsive. Total $\mathrm{N}=242$

Infants whose caregivers are less sensitive have higher levels of cortisol [33, 88] and excess cortisol exposure during early infancy may influence the developing immune response via epigenetics or neuroendocrine dysregulation, potentially leading to $\mathrm{AD}[87,89,90]$. It is also possible that more sensitive mothers take greater care of their infants' skin, by for example, use of moisturizer and regular bathing; however, how this may contribute to the atopic march toward asthma is unclear. To our knowledge, no evidence has been published demonstrating associations among maternal sensitivity, infant skin care, and the atopic march, but these associations are worth exploration as possible rival hypotheses. A recent review summarizing the increasing literature on links between maternal-infant relationships and asthma development, noted that only correlational, not causal links have been established. The review called for randomized controlled trials of social interventions focused on maternal-infant relationships with examination of atopic disease outcomes [44].

Predictors of maternal sensitivity typically include low postpartum depression, anxiety, and stress, high paternal support and adult (as opposed to adolescent) motherhood [91-93]. Depression is known to deplete maternal ability to express positive affect towards her infant, and could possibly be exacerbated by lack of paternal support [91]. Our finding that older adult mothers are more sensitive to their infants is in keeping with research suggesting that younger mothers engage less frequently than older adult mothers in behaviors that promote secure

Table 4 Maternal responsiveness and control, maternal distress, maternal asthma and social support associations with $A D$ at 18 months

\begin{tabular}{llll}
\hline & Unadjusted OR (95\% Cl) & Adjusted OR (95\% Cl) $^{\mathbf{b}}$ & Additional adjustment $^{\mathbf{c}}$ \\
\hline Maternal unresponsiveness & $1.00(0.92-1.09)$ & $1.31(1.04-1.65)^{\mathrm{a}}$ & $1.35(1.05-1.73)^{\mathrm{a}}$ \\
Maternal controlling behaviour & $1.05(0.96-1.14)$ & $1.32(1.04-1.66)^{\mathrm{a}}$ & $1.33(1.03-1.71)^{\mathrm{a}}$ \\
Postnatal depression & $0.97(0.87-1.08)$ & $0.93(0.82-1.05)$ & $0.86(0.74-1.00)$ \\
Pregnancy specific anxiety & $1.57(0.76-3.27)$ & $2.01(0.80-5.06)$ & $2.78(1.04-7.39)^{\mathrm{a}}$ \\
Postnatal anxiety & $1.08(0.98-1.18)$ & $1.13(1.00-1.27)^{\mathrm{a}}$ & $1.16(1.01-1.33)^{\mathrm{a}}$ \\
Maternal asthma (ref: no) & $3.44(1.31-9.02)^{\mathrm{a}}$ & $4.29(1.49-12.29)^{\mathrm{a}}$ & $5.39(1.76-16.5)^{\mathrm{a}}$ \\
Postnatal social support & $0.98(0.96-1.01)$ & & $0.96(0.93-0.99)^{\mathrm{a}}$ \\
\hline
\end{tabular}

a Significant values $\mathrm{p}<0.05$

b Adjusted for maternal unresponsiveness and controlling, postnatal depression and anxiety, pregnancy specific anxiety, maternal asthma

c Additional adjustment for maternal unresponsiveness and controlling, postnatal depression, social support and anxiety, pregnancy specific anxiety, maternal asthma 
attachment, such as positive verbal feedback [94]. But, contrary to much evidence [61, 62, 90, 92, 93, 95], neither maternal stress, anxiety nor breastfeeding were significantly associated with maternal sensitivity. We also observed an unexpected association between higher postnatal depressive symptoms and maternal sensitivity, which may have been due to small sample size. Women reporting excessive depression, anxiety or stress are typically less positively reinforcing and interactive with their infant, thought to lead to poor child development outcomes [22-24, 96]. However, new data from the Avon Longitudinal Study of Parents and Children $(\mathrm{n}=704)$ revealed that perinatal depressive symptoms predicted little variance in maternal-infant relationship qualities, but rather maternal interpersonal sensitivity in pregnancy is the most significant contributor to forming healthy maternal-infant relationships in the context of perinatal depressive symptoms [97]. In other words, other variables that are correlated with both depressive symptoms and qualities of the maternal-child relationship may underpin observed associations between depression and child development and deserve exploration. Moreover, depressive and anxiety symptoms in pregnancy are typically worse than in the postpartum period $[98,99]$, so significant differences would be expected; however, how these differences may influence maternal-child relationships or onset of children's AD is unknown. Studies have shown that high levels of perceived support reported by depressed or anxious mothers may buffer the association with child atopic disease, suggesting accessible support may improve the quality of the mother-child relationship [100-102]. In this study, although greater reported postnatal social support was shown to reduce the likelihood of AD, consistent with various studies [34, 53, 54], social support was not found to be a predictor of sensitive maternal behavior.

Prenatal pregnancy-specific anxiety (adjusted $\mathrm{OR}=2.74 ; 95 \% \mathrm{CI} 1.04,7.19, \mathrm{p}=0.041)$ and postnatal anxiety (adjusted OR $=1.16,95 \%$ CI 1.01, 1.33, $\mathrm{p}=0.034$ ) predicted AD independent of paternal support and maternal sensitivity. A trend for an inverse association between postnatal depression and $\mathrm{AD}$ was also observed. These findings are compatible with several studies on childhood atopic disease associations with maternal prenatal or postnatal stressors $[13,16-18,59$, 103], prenatal anxiety but not depression, as suggested above [88, 104-107]. Mutual adjustment for anxiety and depression may have uncovered the negative influence of postnatal depression on the health care utilization for infant care and thus, physician diagnosis of AD [108]. Consistent with our results, some studies found postnatal anxiety about childrearing to be associated with AD in 3-12 month old infants [15]. As maternal anxiety becomes more prevalent [109], it may gain a more prominent influence on the maternal-infant relationship [97]. Given that low maternal sensitivity and anxiety are interrelated, the association with childhood $\mathrm{AD}$ may be similarly mediated by epigenetics or neuroendocrine dysregulation [88, 104, 110], and altered infant cytokine profiles [111]. Infant neuroendocrine and immunologic maturation is highly plastic in the face of environmental stressors [112-115], especially during the early postnatal period. For those who are already genetically susceptible to the development of atopy [116], as observed in our sample of children whose mothers reported a history of asthma, maternal sensitivity may make the difference between the development of $\mathrm{AD}$ or not.

The pathogenesis of $\mathrm{AD}$ is known to involve abnormal levels of specific cytokines released by T-helper 2 cells detected in cord blood or infant peripheral blood [117-120]. The altered differentiation of these cytokines may be induced through excessive glucocorticoid exposure at an early age, driven by maternal perinatal psychosocial distress [121, 122]. Future research could focus on understanding the associations among: (1) excessive, long-term fetal/infant glucocorticoid exposure during critical developmental periods, (2) Th2 specific cytokine levels in infant cord or peripheral blood, and (3) fetal programming, driven by prenatal distress (anxiety, depression and stress), and (4) poor maternalinfant relationship qualities, linked to postnatal distress. Moreover, genetic risk, suggested by the heritability of atopic disease suggest a need for genome-wide association studies [13].

This study has many strengths, including the outcome of childhood $\mathrm{AD}$ assessed via maternal report of a physician diagnosis of $\mathrm{AD}$ and observational assessment of maternal-infant relationship quality, but there are also limitations. First, physician corroboration of maternal report of physician diagnosis of $\mathrm{AD}$ was not possible. Second, only "maternal" caregiving was assessed; rather than seeking to reinforce gender stereotypes, we recognize that primary caregivers may be mothers, fathers or others. However, we also recognize that the vast majority of infants' primary caregivers are mothers in Canada [123] and in our study [64]. Third, only a small number of mothers reported depressive symptoms in the postpartum period. This may have contributed to the potentially spurious findings of inverse association between postpartum depression and outcomes. Additionally, not all participants reported perceptions of the quality of their partners' support, as only $88 \%$ of participants reported on their child's father. Nonetheless, the variability in primary support provider may also reflect the reality of modern families. Furthermore, while we collected data on maternal asthma, we did not collect additional 
data on mother's atopy status or family history of atopy. Finally, we acknowledge that this is a relatively high SES sample with low sociodemographic risk that may limit generalizability.

To our knowledge, this is the first study to uncover the association between maternal-infant relationship qualities (sensitivity, control, unresponsiveness) and childhood AD after accounting for risk (maternal depression, anxiety and stress) and protective (social support) factors and well-known covariates. We found low maternal sensitivity to be a significant risk factor for childhood AD, in the presence and absence of perinatal anxiety and low social support. Caregivers who are emotionally engaged and supportive of their children during infancy may be well equipped to prevent poor infant immunological development, reducing the likelihood of childhood $\mathrm{AD}$ and potentially asthma [34]. Limited work has begun to establish that interventions focused on the quality of maternal child-relationship may influence asthma symptoms [45]. These results suggest interventions that improve maternal-infant relationship quality, anxiety and support could reduce odds of childhood AD. Existing parenting intervention programs, including the Nurse Family Partnership [124] and Keys to Caregiving [125], and support services may already have effects on $\mathrm{AD}$ and the atopic march, that have not to date been measured. In addition, strengthening of relationships between caregivers serves as a means of controlling maternal anxiety [95] and may therefore be effective in helping prevent childhood AD. Additional intervention studies ought to focus on improving maternal child relationship quality and reducing odds of $\mathrm{AD}$, as a means to forestall the atopic march to allergic rhinitis and ultimately asthma.

\section{Conclusions}

High maternal sensitivity and social support, in combination with low perinatal anxiety, are associated with reduced odds of childhood AD. Higher maternal control and unresponsiveness are associated with increased odds of childhood AD. Clinical assessment of perinatal anxiety, improved social support and the introduction of early intervention programs designed to improve maternal-infant relationship quality may reduce the odds of childhood atopic dermatitis and the progression towards the atopic march, as well as help uncover genetic factors and explanatory neuroendocrine and epigenetic mechanisms.

\footnotetext{
Abbreviations

AD: atopic dermatitis; APrON: Alberta Pregnancy Outcomes and Nutrition; GA: gestational age; CARE-Index: Child-Adult Relationship Experimental-Index; EDS: Edinburgh Depression Scale; SCL-90-R: Symptom Checklist-90 itemRevised; PSAS: Pregnancy-Specific Anxiety Scale; SLEQ: Stressful Life Events Questionnaire; SSEQ: Social Support Effectiveness Questionnaire.
}

\section{Authors' contributions}

NLL, ALK, and NC drafted the manuscript. HNN conducted statistical analysis and compiled all tables and figures. LA and MJH coded and logged participant data. NLL, ALK, HNN, TSC and GFG all contributed to the formulation of study design and data analysis and interpretation. All authors read and revised the manuscript as appropriate and agreed upon this final version. All authors read and approved the final manuscript

\section{Author details \\ ${ }^{1}$ Faculty of Nursing, University of Calgary, Calgary, AB T2N 1N4, Canada. ${ }^{2}$ Cumming School of Medicine, Departments of Pediatrics \& Psychiatry, University of Calgary, Calgary, AB T2N 4N1, Canada. ${ }^{3}$ Departments of Pediat- rics, Obstetrics \& Gynecology, Faculty of Medicine and Dentistry, and School of Public Health, University of Alberta, Edmonton, AB T6G 2R3, Canada. \\ ${ }^{4}$ Department of Psychology, University of Calgary, Calgary, AB T2N 1N4, Can- ada. ${ }^{5}$ Cumming School of Medicine, Department of Pediatrics \& Community Health Sciences, University of Calgary, Calgary, AB T2N 4N1, Canada. ${ }^{6}$ Child Development Centre, ACHRI Owerko Centre, 3rd Floor, 2888 Shaganappi Trail, Calgary, AB T3B 6A8, Canada.}

\section{Acknowledgements}

Generous guidance in accurate formation of variables was provided by Dr. Allan Becker. We would also like to thank the participants of the Alberta Pregnancy Outcomes and Nutrition (APrON) Fetal Programming sub-study for their effort and time commitment given to supporting this research.

\section{Competing interests}

Authors employed by the University of Calgary and University of Alberta.

\section{Availability of data and materials}

The datasets analyzed for this study are not publicly available due to confidentiality agreements but are available from the corresponding author on reasonable request.

\section{Ethics approval and consent to participate}

Ethics approval was obtained from the Conjoint Health Research Ethics Board at the University of Calgary and the Health Research Ethics Board at the University of Alberta, both in Canada. Participation in this study was strictly voluntary and only undertaken once informed consent was provided by each participating individual.

\section{Funding}

Funding for this project was obtained from NCE AllerGen, a CIHR Operating Grant, and the University of Calgary Markin Summer Studentship.

\section{Publisher's Note}

Springer Nature remains neutral with regard to jurisdictional claims in published maps and institutional affiliations.

Received: 8 December 2016 Accepted: 17 May 2017

Published online: 26 May 2017

\section{References}

1. Draaisma $\mathrm{E}$, et al. A multinational study to compare prevalence of atopic dermatitis in the first year of life. Pediatr Allergy Immunol. 2015;26(4):359-66.

2. Spergel JM. Epidemiology of atopic dermatitis and atopic march in children. Immunol Allergy Clin N Am. 2010;30(3):269-80.

3. Lewis-Jones S. Quality of life and childhood atopic dermatitis: the misery of living with childhood eczema. Int J Clin Pract. 2006;60(8):984-92.

4. Carroll $\mathrm{CL}$, et al. The burden of atopic dermatitis: impact on the patient, family, and society. Pediatr Dermatol. 2005;22(3):192-9.

5. Stewart M, et al. Support needs and preferences of young adolescents with asthma and allergies: "just no one really seems to understand". J Pediatr Nurs. 2012;27(5):479-90.

6. Spergel JM, Paller AS. Atopic dermatitis and the atopic march. J Allergy Clin Immunol. 2003;112(6):S118-27. 
7. Spergel JM. From atopic dermatitis to asthma: the atopic march. Ann Allergy Asthma Immunol. 2010;105(2):99-106.

8. Cantani A. The growing genetic links and the early onset of atopic diseases in children stress the unique role of the atopic march: a metaanalysis. J Investig Allergol Clin Immunol. 1998;9(5):314-20.

9. Hahn EL, Bacharier LB. The atopic march: the pattern of allergic disease development in childhood. Immunol Allergy Clin N Am. 2005;25(2):231-46.

10. Lowe AJ, et al. Do boys do the atopic march while girls dawdle? J Allergy Clin Immunol. 2008;121(5):1190-5.

11. Ker J, Hartert TV. The atopic march: what's the evidence? Ann Allergy Asthma Immunol. 2009;103(4):282-9.

12. Andersson $\mathrm{N}$, et al. Prenatal maternal stress and atopic diseases in the child: a systematic review of observational human studies. Allergy. 2016;71(1):15-26.

13. Wen $\mathrm{HJ}$, et al. Prediction of atopic dermatitis in 2-yr-old children by cord blood lgE, genetic polymorphisms in cytokine genes, and maternal mentality during pregnancy. Pediatr Allergy Immunol. 2011;22(7):695-703.

14. Li F, et al. Prevalence and risk factors of childhood allergic diseases in eight metropolitan cities in China: a multicenter study. BMC Public Health. 2011;11(1):437.

15. Pauli-Pott U, Darui A, Beckmann D. Infants with atopic dermatitis: maternal hopelessness, child rearing attitudes and perceived infant temperament. Psychother Psychosom. 1999;68(1):39-45.

16. de Marco R, et al. Foetal exposure to maternal stressful events increases the risk of having asthma and atopic diseases in childhood. Pediatr Allergy Immunol. 2012;23(8):724-9.

17. Hartwig IR, et al. Prenatal adverse life events increase the risk for atopic diseases in children, which is enhanced in the absence of a maternal atopic predisposition. J Allergy Clin Immunol. 2014;134(1):160-9.

18. Bockelbrink A, Heinrich J, Schafer I, Zutavern A, Borte M, Herbath O, Schaaf B, von Berg A, Schafer T. Atopic eczema in children: another harmful sequel of divorce. Allergy. 2006:61(12):1397-402.

19. Grigoriadis S, de Camps Meschino D, Barrons E. Mood and anxiety disorders in a sample of perinatal women referred for psychiatric care. Arch Womens Ment Health. 2011;14:325-33.

20. Gaynes B, et al. Perinatal depression: prevalence, screening, accuracy, and screening outcomes. Research Triangle Park: Agency for Healthcare Research Quality; 2005.

21. Batenburg-Eddes $V$, et al. Parental depressive and anxiety symptoms during pregnancy and attention problems in children: a cross-cohort consistency study. J Child Psychol Psychiatry. 2013;54(5):591-600.

22. Feldman R. Parent-infant synchrony and the construction of shared timing; physiological precursors, developmental outcomes, and risk conditions. J Child Psychol Psychiatry. 2007;48(3-4):329-54.

23. Pearson $R$, et al. Depressive symptoms in early pregnancy disrupt attentional processing of infant emotion. Psychol Med. 2010;40(04):621-31.

24. Warnock FF, et al. Caregiving behavior and interactions of prenatally depressed mothers (antidepressant-treated and non-antidepressant-treated) during newborn acute pain. Infant Ment Health J. 2009;30(4):384-406

25. Letourneau N, et al. Postpartum depression is a family affair: addressing the impact on mothers, fathers, and children. Issues Ment Health Nurs. 2012;33(7):445-57.

26. Field T. Postpartum depression effects on early interactions, parenting and safety practices: a review. Infant Behav Dev. 2011;33:1-6.

27. Glynn LM, Sandman CA. Prenatal origins of neurological development a critical period for fetus and mother. Curr Dir Psychol Sci. 2011;20(6):384-9.

28. Crittenden P. CARE-index infants coding manual. Miami: Family Relations Institute; 2010.

29. Barnard K, Guralnick MJ. Influencing parent-child interactions for children at risk. In: The effectiveness of early interventions. Toronto: Paul Brooks; 1997. p. 99-126.

30. Kelly JF, Zuckerman T, Rosenblatt S. Promoting first relationships: a relationship-focused early intervention approach. Infants Young Child. 2008:21(4):285-95.

31. Conradt E, Ablow J. Infant physiological response to the still-face paradigm: contributions of maternal sensitivity and infants' early regulatory behavior. Infant Behav Dev. 2010;33(3):251-65.
32. Sroufe LA. Attachment and development: a prospective, longitudinal study from birth to adulthood. Attach Hum Dev. 2005;7(4):349-67.

33. Letourneau $\mathrm{N}$, et al. Cortisol patterns of depressed mothers and their infants are related to maternal-infant interactive behaviours. J Reprod Infant Psychol. 2011;29(5):439-59.

34. Suglia SF, et al. Maternal intimate partner violence and increased asthma incidence in children: buffering effects of supportive caregiving. Arch Pediatr Adolesc Med. 2009;163(3):244-50.

35. Thomas JC, et al. Developmental origins of infant emotion regulation: mediation by temperamental negativity and moderation by maternal sensitivity. Dev Psychol. 2017;53(4):611.

36. Hellyer J, et al. Are maternal and community risk factors associated with the presence of asthma among children placed in foster care? Child Youth Serv Rev. 2013;35(1):128-32.

37. Thompson RA. Stress and child development. Future Child. 2014;24(1):41-59.

38. Howlett S. Emotional dysfunction, child-family relationships and childhood atopic dermatitis. Br J Dermatol. 1999;140:381-4.

39. Im Y-J, et al. Parenting and relationship characteristics in mothers with their children having atopic disease. J Child Health Care. 2014;18(3):215-29.

40. Cassibba R, et al. Attachment of mothers and children with recurrent asthmatic bronchitis. J Asthma. 2004;41(4):419-31.

41. Klinnert $M$, et al. Onset and persistence of childhood asthma: predictors from infancy. Pediatrics. 2001;108(4):69-76.

42. Mrazek D. Insecure attachment in severely asthmatic preschool children: is it a risk factor? J Am Acad Child Adolesc Psychiatry. 1987;26(4):516-20.

43. Mrazek $\mathrm{D}$, et al. Prediction of early-onset asthma in genetically at-risk children. Pediatr Pulmonol. 1999;27(2):85-94.

44. Yatsenko O, Pizano J, Nikolaidis A. Revisiting maternal-infant bonding's effects on asthma: a brief history. Cogent Psychol. 2016;3(1):1161267.

45. Madrid A. Helping children with asthma by repairing maternal-infant bonding problems. Am J Clin Hypn. 2006;48(2-3):199-2011.

46. Morsbach SK, Prinz RJ. Understanding and improving the validity of self-report of parenting. Clin Child Fam Psychol Rev. 2006;9(1):1-21.

47. Gardner F. Methodological issues in the direct observation of parentchild interaction: do observational findings reflect the natural behavior of participants? Clin Child Fam Psychol Rev. 2000;3(3):185-98.

48. Aspland H, Gardner F. Observational measures of parent-child interaction: an introductory review. Child Adolesc Ment Health. 2003:8(3):136-43.

49. Emmanuel EN, et al. Maternal role development: the impact of maternal distress and social support following childbirth. Midwifery. 2011;27(2):265-72.

50. Fahey JO, Shenassa E. Understanding and meeting the needs of women in the postpartum period: the perinatal maternal health promotion model. J Midwifery Womens Health. 2013;58(6):613-21.

51. Eastwood JG, et al. Relationship of postnatal depressive symptoms to infant temperament, maternal expectations, social support and other potential risk factors: findings from a large Australian cross-sectional study. BMC Pregnancy Childbirth. 2012;12(1):1.

52. Leung BM, et al. Perinatal nutrition in maternal mental health and child development: birth of a pregnancy cohort. Early Hum Dev. 2016;93:1-7.

53. Rini C, Schetter CD, Glynn L, Hobel C, Sandman C. Effective social support: antecedents and consequences of partner support during pregnancy. Pers Relatsh. 2006;13:207-29.

54. Rini C, Schetter CD. The effectiveness of social support in intimate relationships. In: Davila KSJ, editor. Support processes in intimate relationships. New York: Oxford; 2010. p. 26-67.

55. Letourneau N, et al. Postpartum depression: maternal and service providers' perspectives of support needs. In: International institute for qualitative methodology conference, Edmonton, AB. 2005.

56. Dennis $C$, Letourneau N. Global and relationship-specific perceptions of support and the development of postpartum depressive symptomatology. Soc Psychiatry Psychiatr Epidemiol. 2007:42(5):389-95.

57. Purvis $D$, et al. Risk factors for atopic dermatitis in New Zealand children at 3-5 years of age. Br J Dermatol. 2005;152(4):742-9.

58. Doğruel D, Bingöl G, Altıntaş DU, Yılmaz M, Kendirli SG. Prevalence of and risk factors for atopic dermatitis: a birth cohort study of infants in southeast Turkey. Allergol Immunopathol. 2016;44(3):214-20. 
59. Wen $\mathrm{HJ}$, et al. Predicting risk for early infantile atopic dermatitis by hereditary and environmental factors. Br J Dermatol. 2009;161(5):1166-72.

60. Kerkhof $M$, et al. Risk factors for atopic dermatitis in infants at high risk of allergy: the PIAMA study. Clin Exp Allergy. 2003;33(10):1336-41.

61. Tharner $A$, et al. Breastfeeding and its relation to maternal sensitivity and infant attachment. J Dev Behav Pediatr. 2012;33(5):396-404.

62. Benn CS, et al. Breastfeeding and risk of atopic dermatitis, by parental history of allergy, during the first 18 months of life. Am J Epidemiol. 2004; 160(3):217-23.

63. Giesbrecht GF, Letourneau N, Campbell TS. Sexually dimorphic and interactive effects of prenatal maternal cortisol and psychological distress on infant cortisol reactivity. Dev Psychopathol. 2016. doi:10.1017/ S0954579416000493.

64. Kaplan BJ, et al. The Alberta pregnancy outcomes and nutrition (APrON) cohort study: rationale and methods. Matern Child Nutr. 2014;10(1):44-60.

65. Von Kobyletzki LB, Janson S, Hasselgren M, Bornehag CG, Svensson Å. Evaluation of a parental questionnaire to identify atopic dermatitis in infants and preschool children. J Allergy. 2012;2012:945617.

66. Crittenden P, Bonvillian J. The effect of maternal risk status on maternal sensitivity to infant cues. Am J Orthopsychiatry. 1984:54:250-62.

67. DiLalla D, Crittenden P. Dimensions of maltreated children's home behavior: a factor analytic approach. Infant Behav Dev. 1990;13:439-60.

68. Ward M, Carlson E. Associations among adult attachment representations, maternal sensitivity, and infant-mother attachment in a sample of adolescent mothers. Child Dev. 1995;66:69-79.

69. Leadbeater BJ, Bishop S, Raver C. Quality of mother-toddler interaction, maternal depressive symptoms, and behavioral problems of adolescent mothers. Dev Psychol. 1996;32:280-8.

70. Leventhal A, et al. Caregiver attitudes and at-risk maternal behavior among mothers with major mental illness. Psychiatr Serv. 2004;55:1431-3.

71. Crittenden P, DiLalla D. Compulsive compliance: the development of an inhibitory coping strategy in infancy. J Abnorm Child Psychol. 1988;16:585-99.

72. Azar R, et al. The association of major depression, conduct disorder, and maternal overcontrol with a failure to show a cortisol buffered response in 4-month-old infants of teenage mothers. Biol Psychiatry. 2007;62(6):573-9.

73. Cox JL, Holden JM, Sagovsky R. Detection of postnatal depression: development of the 10-item Edinburgh Postnatal Depression Scale. Br J Psychiatry. 1987;150:782-6.

74. Matthey S. Differentiating between transient and enduring distress on the Edinburgh Depression Scale within screening contexts. J Affect Disord. 2016;196:252-8.

75. Derogatis L. Symptom checklist-90-R: administration, scoring and procedures manual. Minneapolis: NCS Pearson Inc; 1994.

76. Rini C, et al. Psychological adaptation and birth outcomes: the role of personal resources, stress, and sociocultural context in pregnancy. Health Psychol. 1999;18(4):333-45.

77. Barnett B, Hanna B, Parker G. Life event scales for obstetric groups. J Psychosom Res. 1983;27:313-20.

78. Jomeen J, Martin C. Replicability and stability of the multidimensional model of the Edinburgh Postnatal Depression Scale. J Psychiatr Ment Health Nurs. 2007;14:319-24.

79. Boyd R, Pearson J, Blehar M. Prevention and treatment of depression in pregnancy and the postpartum period-summary of a maternal depression roundtable: a US perspective. Arch Womens Ment Health. 2002;4:79-83.

80. Morgan CD, Wiederman MW, Magnus RD. Discriminant validity of the SCL-90 dimensions of anxiety and depression. Assessment. 1998;5(2):197-201.

81. Bergink $V$, et al. Validation of the Edinburgh Depression Scale during pregnancy. J Psychosom Res. 2011;70(4):385-9.

82. Bergman K, et al. Quality of child-parent attachment moderates the impact of antenatal stress on child fearfulness. J Child Psychol Psychiatry. 2008;49(10):1089-98.

83. Bergman $\mathrm{K}$, et al. Maternal stress during pregnancy predicts cognitive ability and fearfulness in infancy. J Am Acad Child Adolesc Psychiatry. 2007:46:1454-63.
84. Stapleton LRT, et al. Perceived partner support in pregnancy predicts lower maternal and infant distress. J Fam Psychol. 2012;26(3):453.

85. Giesbrecht GF, et al. The buffering effect of social support on hypothalamic-pituitary-adrenal axis function during pregnancy. Psychosom Med. 2013;75(9):856-62.

86. Hosmer DW, Lemeshow S, Sturdivant RX. Applied logistic regression, vol. 398. New York: Wiley; 2013.

87. Kilpeläinen $M$, et al. Stressful life events promote the manifestation of asthma and atopic diseases. Clin Exp Allergy. 2002;32(2):256-63.

88. Wang IJ, Wen HJ, Chiang TL, Lin SJ, Guo YL. Maternal psychologic problems increased the risk of childhood atopic dermatitis. Pediatr Allergy Immunol. 2016;27(2):169-76.

89. Wright RJ. Stress and atopic disorders. J Allergy Clin Immunol. 2005;116(6):1301-6.

90. Chida Y, Hamer M, Steptoe A. A bidirectional relationship between psychosocial factors and atopic disorders: a systematic review and meta-analysis. Psychosom Med. 2008;70(1):102-16.

91. Crockenberg SC, Leerkes EM. Parental acceptance, postpartum depression, and maternal sensitivity: mediating and moderating processes. J Fam Psychol. 2003;17(1):80.

92. Goldstein LH, Diener ML, Mangelsdorf SC. Maternal characteristics and social support across the transition to motherhood: associations with maternal behavior. J Fam Psychol. 1996;10(1):60.

93. Tietz A, Zietlow A-L, Reck C. Maternal bonding in mothers with postpartum anxiety disorder: the crucial role of subclinical depressive symptoms and maternal avoidance behaviour. Arch Womens Mental Health. 2014;17(5):433-42.

94. Demers I, et al. Mind-mindedness in adult and adolescent mothers: relations to maternal sensitivity and infant attachment. Int J Behav Dev. 2010;34(6):529-37.

95. Pilkington $\mathrm{PD}$, et al. Modifiable partner factors associated with perinatal depression and anxiety: a systematic review and meta-analysis. J Affect Disord. 2015:178:165-80.

96. Kingston D, Tough S, Whitfield H. Prenatal and postpartum maternal psychological distress and infant development: a systematic review. Child Psychiatry Hum Dev. 2012;43(5):683-714.

97. Raine $K$, et al. Antenatal interpersonal sensitivity is more strongly associated than perinatal depressive symptoms with postnatal mother-infant interaction quality. Arch Womens Ment Health. 2016;19(5):917-25.

98. Gavin NI, et al. Perinatal depression: a systematic review of prevalence and incidence. Obstet Gynecol. 2005;106(5, Part 1):1071-83.

99. Giardinelli L, et al. Depression and anxiety in perinatal period: prevalence and risk factors in an Italian sample. Arch Womens Ment Health. 2012;15(1):21-30

100. dos Santos LM, et al. Maternal mental health and social support: effect on childhood atopic and non-atopic asthma symptoms. J Epidemiol Community Health. 2012;66(11):1011-6.

101. Mangan JM, Wittich AR, Gerald LB. The potential for reducing asthma disparities through improved family and social function and modified health behaviors. CHEST J. 2007;132(5_suppl):7895-801S.

102. Chen $\mathrm{E}$, et al. The role of the social environment in children and adolescents with asthma. Am J Respir Crit Care Med. 2007;176(7):644-9.

103. Li F, et al. Prevalence and risk factors of childhood allergic diseases in eight metropolitan cities in China: a multicenter study. BMC Public Health. 2011;11(1):1.

104. Chang HY, Suh DI, Yang SI, Kang MJ, Lee SY, Lee E, Choi IA, Lee KS, Shin YJ, Shin YH, Kim YH. Prenatal maternal distress affects atopic dermatitis in offspring mediated by oxidative stress. J Allergy Clin Immunol. 2016;138(2):468-75.

105. Cookson $\mathrm{H}$, et al. Mothers' anxiety during pregnancy is associated with asthma in their children. J Allergy Clin Immunol. 2009:123(4):847-53.

106. Beijers $\mathrm{R}$, et al. Maternal prenatal anxiety and stress predict infant illnesses and health complaints. Pediatrics. 2010;126(2):e401-9.

107. Cheng TS, et al. An independent association of prenatal depression with wheezing and anxiety with rhinitis in infancy. Pediatr Allergy Immunol. 2015;26(8):765-71.

108. Field T. Postpartum depression effects on early interactions, parenting, and safety practices: a review. Infant Behav Dev. 2010;33(1):1-6.

109. Fairbrother $\mathrm{N}$, et al. Perinatal anxiety disorder prevalence and incidence. J Affect Disord. 2016;200:148-55. 
110. Essex MJ, et al. Maternal stress beginning in infancy may sensitize children to later stress exposure: effects on cortisol and behavior. Biol Psychiatry. 2002;52(8):776-84

111. Andersson NW, et al. Influence of prenatal maternal stress on umbilical cord blood cytokine levels. Arch Womens Ment Health. 2016;19(5):761-7.

112. Mathilda Chiu Y-H, et al. Prenatal and postnatal maternal stress and wheeze in urban children: effect of maternal sensitization. Am J Respir Crit Care Med. 2012;186(2):147-54.

113. Alkon A, et al. The ontogeny of autonomic measures in 6-and 12-month-old infants. Dev Psychobiol. 2006:48(3):197-208.

114. Gunnar MR, Donzella B. Social regulation of the cortisol levels in early human development. Psychoneuroendocrinology. 2002;27(1):199-220.

115. De Luca G, et al. Fetal and early postnatal life roots of asthma. J Matern Fetal Neonatal Med. 2010;23(sup3):80-3.

116. Cho H-J, et al. Effect of prenatal maternal trait anxiety on atopic dermatitis and immunoglobulin E Level: cocoa study. J Allergy Clin Immunol. 2015;135(2):AB263.

117. Von Hertzen LC. Maternal stress and T-cell differentiation of the developing immune system: possible implications for the development of asthma and atopy. J Allergy Clin Immunol. 2002;109(6):923-8.
118. Wright RJ, et al. Prenatal maternal stress and cord blood innate and adaptive cytokine responses in an inner-city cohort. Am J Respir Crit Care Med. 2010;182(1):25-33.

119. Seckl JR, Holmes MC. Mechanisms of disease: glucocorticoids, their placental metabolism and fetal 'programming' of adult pathophysiology. Nat Clin Pract Endocrinol Metab. 2007;3(6):479-88.

120. Seneviratne $S L$, et al. Allergen-specific CD8+ T cells and atopic disease. J Clin Investig. 2002;110(9):1283-92.

121. Giesbrecht G, Campbell T, Letourneau N, Kooistra L, Kaplan B, APrON Study Team. Psychological distress and salivary cortisol covary within persons during pregnancy. Pscyhoneuroendocrinology. 2011;27(1-2):171-80.

122. Wright RJ, Enlow MB. Maternal stress and perinatal programming in the expression of atopy. Expert Rev Clin Immunol. 2008;4(5):535.

123. Findlay $L$, Kohen D. Leave practices of parents after the birth or adoption of young children. Can Soc Trends. 2012. No. 11-008-X

124. Olds DL. The nurse-family partnership: an evidence-based preventive intervention. Infant Ment Health J. 2006;27(1):5-25.

125. Spietz A, et al. Keys to caregiving manual. Seattle: NCAST; 1990.

\section{Submit your next manuscript to BioMed Central and we will help you at every step:}

- We accept pre-submission inquiries

- Our selector tool helps you to find the most relevant journal

- We provide round the clock customer support

- Convenient online submission

- Thorough peer review

- Inclusion in PubMed and all major indexing services

- Maximum visibility for your research

Submit your manuscript at www.biomedcentral.com/submit 